\title{
Mechanism, Diagnosis, Medication, Care Guidance, and Health Promotion in Alzheimer's Disease
}

\author{
Yue DONG ${ }^{1, *}$ \\ ${ }^{1}$ University of Miami, Miami, US
}

\begin{abstract}
Alzheimer's Disease (AD) is one of the most serious and prevalent medical conditions, manifested by memory loss and daily activity dysfunction. Many established hypotheses regarding AD, such as A $\beta$ peptide aggregation and tau tanglements, have provided a fundamental basis. Despite the progress, AD still possesses irreversibility, and the current treatments generated towards $\mathrm{AD}$ only aimed to slow down progression. Therefore, further studies on $\mathrm{AD}$ mechanism, diagnosis, medication, care guidance, health care and health promotion are constantly conducted for enhancement and advancement. This review article briefly demonstrates long-established facts and sums up the recent discoveries on AD.
\end{abstract}

\section{Introduction}

By 2020, AD's prevalence in people over age 65 is $10 \%$ in the U.S, making up to 5.8 million people [1]. The aging of the "baby boomer" generation, the increased life expectancy led by advanced treatments, and higher detection rates led by enhanced medical technology are contributing to the increase of AD's prevalence, making it the third cause of death in the US instead of the fifth [2]. $\mathrm{AD}$ is mainly classified into two groups: late-onset Alzheimer's Disease (LOAD), accounting for 95\% of hospitalized $\mathrm{AD}$ patients, and Autosomal-Dominant inherited Alzheimer's Disease (DIAD), accounting for less than 1 percent.

Over decades, many famous hypotheses regarding the mechanism of $\mathrm{AD}$ were proposed, such as beta-amyloid (A $\beta$ ) plaque aggregation and neurofibrillary tangles of TAU, APOE genetic risks, synaptic vulnerability and mitochondrial dysfunction [3]. These hypotheses promoted medical diagnoses and treatments on the molecular level, but AD's pathogenesis nevertheless remains irreversible and uncurative.

Luckily, with the introduction of epigenetics in $\mathrm{AD}$ field, scientists are able to detect many inheritable but non-genetic risk factors. Epigenetics-targeted diagnostic tool and medication are designed accordingly, enhancing precision. What is more, recent PICOs and clinical researches promoted and standardized pre-diagnosis and post-diagnosis care in hospital and community settings with the increasing attention on enhancing healthcare system proficiency and family-centered care. In this paper, the newest researches of AD on both molecular and clinical levels will be systematically summed up.

\section{Overview of Alzheimer's Disease}

$\mathrm{AD}$ takes up $65 \%$ of the dementia population companied by many well-known symptoms. During the progression of $\mathrm{AD}$, patients undergo brain cells damage starting at the entorhinal cortex and hippocampus, and then affecting cerebral cortex. Apraxia, inability to execute action; agnosia, sensory loss; anomia, inability to match objects with words; aphasia, speaking difficulties are the four characteristics to describe patients with AD. At an early stage, patients suffer from normal aging processes, such as memory loss. From the moderate to late stage, patients' personality usually alters dramatically with disorientation. When reaching late-stage $\mathrm{AD}, \mathrm{ADL}$ of patients is likely to become impaired and bedridden with possible seizures.

\section{Traditional Molecular Mechanism of AD}

Mand diagnosis and treatments are based on amyloid aggregation hypothesis. In $\mathrm{AD}$ prognosis, $10 \%$ of amyloid protein precursor (APP) goes through proteolysis catalyzed by $\beta$ - and $\gamma$ - secretase and are disassembled into sAPP $\beta, A C I D$, and $A \beta$ [4]. The formation of $A \beta$ is normal, but the decreased ability to degrade $A \beta$ contributes to plaque formation, mainly composed of $A \beta_{40}$ and $A \beta_{42}$. There are many risk factors for imbalanced $A \beta$ metabolism such as aging, decreased metabolic rhythm, pathogenic mutation of APP and $\gamma$ - secretase etc [5]. The senile plaque possesses its neurotoxicity due to the conflation of $\mathrm{A} \beta \mathrm{s}$ from monomers to dimers then to oligomers. Because of clearance incompetence, DIAD and LOAD patients suffer from dilatory neurotransmission and neural activity. 
Tau hyperphosphorylation is another mainstream concept. Because of the elevated phosphorylation level of tau, an important protein for microtubules stabilities in neurons, paired helical filament (PHF) of tau and neurofibrillary tanglements are formed. All of those processes weaken the interneuron signaling and communication and normal intraneuron growth in $\mathrm{AD}$ patients, ending in the atrophy seen in PET scan [6].

Aside from those well-established hypotheses, certain genes are proved to be relevant to $\mathrm{AD}$ as well. For DIAD, APP gene on chromosomal 21, presenilin 1 (PS1) gene on chromosomal 14, and presenilin 2 (PS2) gene on chromosomal 1 mutation are indications of early-onset $\mathrm{AD}$ with an average age of 45. Down's Syndrome with an additional chromosomal 21 exhibits the more potential for AD-like pathology, given the 50\% duplication of APP [7]

Moreover, apolipoprotein (APOE), well known for its transportation of fat intracellularly and extracelluarly by binding lipids. APOE is recognized as a major risk factor for LOAD, delivering cholesterol in and out of the brain. APOE gene doesn't possess strong Mendelian character. APOE gene's polymorphism, including APOE2, 3 and 4, reflects on different inferences on LOAD prognosis, and APOE4 is shown to have the most correlation with $A D$ [3].

As discussed above, the traditional hypothesis and genetic factors of $\mathrm{AD}$ are well understood. However, it is not until recent years when epigenetics receive large attention.

\subsection{Epigenetics}

The control and regulation of the degree of gene expression, known as epigenetics, matter as much as genome itself, and cannot be even more. Instead of changing genetic sequence, the attachment or detachment of chemical groups on DNA sequence can have an inhibiting or a boosting effect on gene expression, and therefore, influence phenotype. Other than the wellknown DNA methylation and histone modification, there are also non-coding RNA and ncRNA regulations [8]. More importantly, epigenetics works as a mediator between gene and environment. Any kind of physical, mental, or lifestyle changes in one's life may potentially alter gene expression by epigenetic modification. Hence, epigenetics may be the cause of many diseases, including AD triggered by environment instead of conventional genetics only.

According to [9], epigenetics is mitotically heritable due to DNMT3a\&b's mitotic inheritance, linking the progression of $\mathrm{AD}$ to epigenetics. Moreover, there is a possibility that transgenerational epigenetics inheritance (TEI) could be applied to human as researches go further [10]. What is more, epigenetics engages in memory and learning genesis. Thus, Epigenetics' profound and diverse influence on $\mathrm{AD}$ discussed below promotes a better understanding of $\mathrm{AD}$ prognosis and inspires new diagnostic tools and medication.

\section{- DNA Methylation}

DNA methylation is the addition of methyl groups to cytosines mainly on DNA's CpG islands. This process is catalyzed by DNA methyltransferase (DNMT), and the methyl group was released from donor SAM (S-adenosylL-methionine). One of DNA methylation's important rules is to silence certain DNA fragments by attaching a repressor or inactivating promoter region [11]. On the other hand, hydroxy-methylation, the additional hydroxylation on 5-methylcytosine $(5 \mathrm{mc})$ into 5hydroxymethylcytosine $(5 \mathrm{hmc})$, upregulate genes expression by mediating DNA methylation [12]. An adequate amount of DNA is normal physiology, but excessive or insufficient methylation might be the trigger of $\mathrm{AD}$ or abet the progression of $\mathrm{AD}$.

Many studies of global DNA methylation exist in the temporal cortex, frontal cortex, and hippocampus cortex because of the clear brain atrophy of AD patients. DNA methylation is conjectured to have cell-type and region specificity. However, there are many controversies of whether certain brain region is hypomethylated or hypermethylated[13]. Yokoyama and colleagues summarized DNA methylation's influence on AD's function. The hypermethylation of Tbxa2r and Sorbs3 gene, as well as the hypomethylation of CRTC1 contributes to AD's degradation of neuroplasticity, compensating its ability to adapt to new factors, such as injuries. Moreover, the changing level of methylation of IL- $1 \mathrm{~b}$ and IL- 6 triggers the swing of the inflammation process in the early and late stages of AD.

DNA demethylation of APP gene is related to AD. 5, of APP gene is full of $\mathrm{CpG}$ islands, enabling methylation. It is found in AD patients' brain that APP gene is more likely to be demethylated than people without AD. Factors, like lead or folic acid antagonist, will bring down the methylation level of APP and subsequently activate BACE1gene for $\beta$-secretase formation. Therefore, the methylation contributes more to the $A \beta$ aggregation on AD progression [14] \& [15]. Moreover, BRCA1 gene, a well-known tumor suppressor gene, has the tendency for overexpression by hypomethylation in patients with $\mathrm{AD}$ [16].

- Chromosomal remodeling and histone modification

Histones are protein subunits important in posttranslational regulation. Histones together DNA are assembled into a nucleosome, the basic unit of chromatin. Histones' N-terminal tails are on the outside of nucleosomes, making it active for many epigenetic modifications, among which acetylation is methylation, acetylation, phosphorylation and ubiquitination, and acetylation is studied the most [11].

Compared with the mechanism of DNA methylation, the deacetylation of histones downregulates gene expression. Histone deacetylation will turn the relaxed structure into a condensed one by increasing histone's Ntermini interaction with DNA phosphate group, catalyzed by histone deacetylases (HDAC). According to [8], different classes of HDAC have varied concentrations distributing in the brain, and many studies have shown the correlation between the level of HDACs and AD, including its impact on cognitive impairments, neurodegenerations, tau acetylation, and so on. The below Tabel 1 highlighted the most often discussed HDAC [17]. In response to over expression of most of the HDACs, 
HDAC inhibitors are produced for pan-HDAC inhibition or specific HDAC inhibition.

- $m i R N A$

Micro-RNAs (miRNA) are small fragments of noncoding RNA (ncRNA) that are transcribed but not translated from DNA. While storing in the RNA silencing complex (RISC), miRNA halts the transcription or cleavage of certain mRNA by base-pairing with complementary part of the mRNA with 3'UTR as targetgenes [11]. Therefore, miRNA has an effect on downregulating certain genes. What is more, one single miRNA can combine with hundreds of gene, expanding its influence on biological pathway regulation.

Many studies exhibit positive or reverse correlations between miRNA and AD's progression. The downregulation or upregulation of certain miRNA influence $A \beta$ aggregation process, BDNF function and neurogenesis as discussed below Table [8] \& [18]. Because of miRNA's specificity towards AD pathogenesis, its use as a biomarker for AD diagnosis is constantly studied.

Table1. Major HDAC Classification

\begin{tabular}{|c|c|c|c|}
\hline Class & Name & Association with AD & Mechanism and correlation \\
\hline Class I & HDAC2 & $\begin{array}{l}\text { Found highly expressed in } \\
\text { hippocampus and prefrontal } \\
\text { cortex }\end{array}$ & $\begin{array}{l}\text { Reduction of HDAC2 expression alleviates } \\
\text { amyloid aggregation and restore cognitive } \\
\text { function; } \\
\text { Overexpression of HDAC } 2 \text { fastens } \\
\text { neurodegeneration and memory formation. }\end{array}$ \\
\hline Class II & HDAC4 & Dysregulated & $\begin{array}{l}\text { Related to synaptic plasticity and memory } \\
\text { formation. Aberrant expression of HDAC4 } \\
\text { contributes to cognitive decline }\end{array}$ \\
\hline & HDAC6 & $\begin{array}{l}\text { Highly expressed in cortex and } \\
\text { hippocampus }\end{array}$ & $\begin{array}{l}\text { Reduction of HDAC6 decrease level tau } \\
\text { phosphorylation and enhance cognitive } \\
\text { impairment }\end{array}$ \\
\hline Class III & SIRT1 & $\begin{array}{l}\text { The decline of expression in } \\
\text { cortex }\end{array}$ & $\begin{array}{l}\text { Reduction level of SIRTI can cause tau } \\
\text { acetylation and therefore lead to tau } \\
\text { aggregation. }\end{array}$ \\
\hline
\end{tabular}

\begin{tabular}{|l|l|l|l|}
\hline Name/ class & Function & Alteration in AD & Association with AD \\
\hline miRNA-9 & $\begin{array}{l}\text { Stem cell differentiation } \\
\text { Target neurofilament H } \\
\text { Target SIRT1 }\end{array}$ & Downregulation in B5,6 & $\begin{array}{l}\text { Neurodegeneration } \\
\text { Tau phosphorylation }\end{array}$ \\
\hline miRNA-132 & $\begin{array}{l}\text { Activator of neuronal } \\
\text { process outgrowth } \\
\text { Regulate BDNF }\end{array}$ & $\begin{array}{l}\text { Decreased expression in B3,4 } \\
\text { hippocampus } \\
\text { B5,6 hippocampus \& medial } \\
\text { frontal gyrus }\end{array}$ & Neurodegeneration \\
\hline miR-146a & & Upregulated & $\begin{array}{l}\text { Further exacerbate } \\
\text { neuroinflammation }\end{array}$ \\
\cline { 3 - 4 } $\begin{array}{l}\text { miR-146b } \\
\text { miR-181a } \\
\text { miR-1425p } \\
\text { miR191 } \\
\text { miR221 } \\
\text { miR-142 } \\
\text { miR-15b }\end{array}$ & Immune system regulator & Downregulation & $\begin{array}{l}\text { Result of invigorative } \\
\text { immune pathway in AD }\end{array}$ \\
\hline
\end{tabular}

Table2. Relationship between alterted regulation of miRNA and the progression of AD

\begin{tabular}{|c|c|c|c|}
\hline Name/ class & Function & Alteration in AD & Association with AD \\
\hline miRNA-145 & Inhibit IRS-1 & $\begin{array}{l}\text { Upregulation in B5,6 } \\
\text { medial frontal gyrus }\end{array}$ & Induction of diabetes \\
\hline miR-15a & \multirow{2}{*}{$\begin{array}{l}\text { Target pro-apoptotic } \\
\text { Target tau kinase }\end{array}$} & Downregulation & \\
\hline $\operatorname{miR}-15 b$ & & $\begin{array}{l}\text { Decrease in CSF but } \\
\text { not in AD brain }\end{array}$ & Tau hyperphosphorylation \\
\hline miR-107 & $\begin{array}{l}\text { Target BACE1 and cofilin } \\
\text { Induce cell cycle arrest } \\
\text { Target Dicer }\end{array}$ & Downregulation & $\begin{array}{l}\text { Increase cell- cycle re-entry } \\
\text { marker }\end{array}$ \\
\hline $\operatorname{miR}-106 b$ & Target cell cycle regulation & Downregulation & $\begin{array}{l}\text { a compensatory mechanism } \\
\text { to cell cycle reentry; } \\
\text { increase APP protein }\end{array}$ \\
\hline
\end{tabular}




\begin{tabular}{|l|l|l|l|}
\hline miR-29b & $\begin{array}{l}\text { Neuronal homeostasis, target a family } \\
\text { of pro-apoptotic regulators, } \\
\text { Target BACE1 }\end{array}$ & Downregulate & $\begin{array}{l}\text { Increase pro-apoptotic } \\
\text { markers, induce } \\
\text { neurodegeneration }\end{array}$ \\
\hline miR-181c & $\begin{array}{l}\text { Hematopoietic differentiation } \\
\text { Regulator of cellular defense } \\
\text { mechanism }\end{array}$ & $\begin{array}{l}\text { Downregulation in AD } \\
\text { cortex and CSF }\end{array}$ & $\begin{array}{l}\text { Amyloid plaque formation } \\
\text { Less control of ROS for DNA } \\
\text { damage }\end{array}$ \\
\hline
\end{tabular}

\subsection{Stem Cell Technique}

A new study published in 2019 by Meyer and colleagues uncovered the potential characteristics for neurons in patients with $\mathrm{AD}$ and protein REST's up-to-minute relation with $\mathrm{AD}$. [19] Post-mortem data regarding $\mathrm{AD}$ is unstable for researching mechanism, and transgenic animal models have its limitation. In order to obtain a better understanding of $\mathrm{AD}$, this study used induced progenitor stem cell technique to revert skin cells of people with and without $\mathrm{AD}$ into undifferentiated state and then mature them into neural progenitors. Studies have found out that, on the one hand, those neural progenitors in people with $\mathrm{AD}$ are ahead of time for gaining complete function and are relative of great quantity. On the other hand, those neurons have the characteristics of prematurity: the nuclei and the membranes are more prone to abnormality than a normal neuron. Thus, this study put forward neurons' own contribution towards $\mathrm{AD}$ progression. What is more, the reduction of protein REST in patients with $\mathrm{AD}$ exploit a new hypothesis towards AD pathology. Protein REST

(repressor element 1-silencing factor), a transcriptional repressor, is essential in CNS cell differentiation and was found independent of traditional $A \beta$ aggregation and tau fibrillatory. Therefore, further research into this protein might discover a new area for AD progression [19].

\section{Screening and Diagnosis}

\subsection{Tradition}

A lot of physical and mental tests for diagnosis or screening of $\mathrm{AD}$ are developed over the years including medical history, mental status exam, lab tests, imaging test, post-mortem examination. The screening of dementia, especially $\mathrm{AD}$, is consisted of two visits for primary care physicians. On the first visit, screening tests, like the verbal fluency test, the Mini-Cognitive Assessment Instrument, or the Sweet 16 followed by lab or imaging tests are done. On the second visit, Mini-Mental State Examination, Geriatric Depression Scale, verbal fluency, and clock drawing tests will be done [20]. The specific method, sensitivity, and specificity are concluded in Table 3 below [21] \& [4].

Table3. Screening test for Alzheimer's Disease diagnosis

\begin{tabular}{|l|l|l|l|l|}
\hline Tool name & Demonstration & Score standard & Sensitivity & Specificity \\
\hline Verbal fluency test & $\begin{array}{l}\text { Name animals in } 60 \\
\text { seconds }\end{array}$ & $\begin{array}{l}<15: \text { suggestion of } \\
\text { dementia } \\
<12 \text { with 1-7 years of } \\
\text { education } \\
<9 \text { with no education }\end{array}$ & 0.88 & 0.96 \\
\hline $\begin{array}{l}\text { Mini-Cognitive } \\
\text { Assessment } \\
\text { Instrument }\end{array}$ & $\begin{array}{l}\text { Three item recall (3) } \\
\text { Clock drawing (2) }\end{array}$ & $\begin{array}{l}\text { dementia } \\
0-2 \text { high likelihood of } \\
\text { dementia }\end{array}$ & 0.76 & 0.89 \\
\hline Sweet 16 & $\begin{array}{l}\text { Three item recall (3) } \\
\text { Eight-item orientation (8) } \\
\text { Backward digit span (5) }\end{array}$ & $\begin{array}{l}<14: \text { suggestion of } \\
\text { dementia }\end{array}$ & 0.80 & 0.70 \\
\hline $\begin{array}{l}\text { Mini-Mental State } \\
\text { Examination }\end{array}$ & $\begin{array}{l}\text { orientation, attention, } \\
\text { memory, language and } \\
\text { visual-spatial skills (3) }\end{array}$ & $\begin{array}{l}<20: \text { suggestion of } \\
\text { dementia }\end{array}$ & 0.85 & 0.9 \\
\hline $\begin{array}{l}\text { Geriatric Depression } \\
\text { Scale - Short Form }\end{array}$ & Yes/ No question (15) & & 0.9 & 0.9 \\
\hline
\end{tabular}

Numbers between parentheses are the number of testes items.

There is currently no diagnostic laboratory test for AD. Many laboratory tests are conducted to rule out the possibility of other types of dementia or reversible illness as the physicians see fit. By ruling out other reversible effects, such as nutrient deficiency, hormonal imbalance, and infected disease as discussed in Table 4, HCP can better assist with patients' need and step to the next level of testing: brain imaging and genetic testing, which is rare.
From CT and MRI, stroke and brain atrophy can be detected [22]. Whereas from PET, molecular signatures of $\mathrm{AD}$, such as amyloid deposition, tau pathology, glucose metabolism, and neuroinflammation can are able to be found through certain radiotracers in different brain regions shown in Table 5 [23].

Though current AD prognosis is systematic, screening tests for AD cannot guarantee specificity and sensitivity. Laboratory results can only function as an axillary tool, and PET and CSF tests are relatively invasiveness and of 
high expenditure. Many new proposed detection methods bring more accurate and efficient methods for diagnosis and might have the potential to forward the attention of $\mathrm{AD}$ to prevention level.

Table4. General lab testing for AD

\begin{tabular}{|c|c|c|}
\hline TEST & SAMPLE & $\begin{array}{c}\text { ASSOCIATED } \\
\text { WITH }\end{array}$ \\
\hline Vitamin B12 & Blood & B12 deficiency \\
\hline T4 & Blood & Thyroid disorder \\
\hline
\end{tabular}

\begin{tabular}{|c|c|c|}
\hline TEST & SAMPLE & $\begin{array}{c}\text { ASSOCIATED } \\
\text { WITH }\end{array}$ \\
\hline TSH & Blood & Thyroid disorder \\
\hline CBC & Blood & Anemia, infection \\
\hline Electrolytes & Blood & $\begin{array}{c}\mathrm{Na}+, \mathrm{K}+, \mathrm{Cl}-, \mathrm{CO} 2 \\
\text { and } \mathrm{pH} \text { imbalance }\end{array}$ \\
\hline CRP, ESR & Blood & Inflammation \\
\hline HIV antibody & Blood & HIV/AIDS \\
\hline Syphilis test & Blood & Syphilis \\
\hline Drug screen & Urine & Illicit drug use \\
\hline
\end{tabular}

Table5. Imaging alzheimer's disease pathophysiology with PET[23]

\begin{tabular}{|c|c|c|c|}
\hline Biological target & Radiotracers & Findings & Typical brain regions involved \\
\hline Amyloid deposition & $\begin{array}{l}{[11 \mathrm{C}] \text { PIB }} \\
{[18 \mathrm{~F}] \text { Florbetapir }} \\
{[18 \mathrm{~F}] \text { Florbetaben }} \\
{[18 \mathrm{~F}] \text { Flutemetamol }} \\
{[18 \mathrm{~F}] \text { NAV4694 }}\end{array}$ & $\begin{array}{l}\text { Increased } \\
\text { retention }\end{array}$ & $\begin{array}{l}\text { Frontal cortex, medial and lateral posterior parietal } \\
\text { cortices, precuneus } \\
\text { Occipital cortex, lateral, temporal cortices and } \\
\text { striatum }\end{array}$ \\
\hline Tau pathology & $\begin{array}{l}{[18 \mathrm{~F}] \mathrm{T} 807} \\
{[18 \mathrm{~F}] \mathrm{T} 808} \\
{[18 \mathrm{~F}] \mathrm{THK} 523} \\
{[18 \mathrm{~F}] \mathrm{THK} 5105} \\
{[18 \mathrm{~F}] \mathrm{THK} 5117} \\
{[11 \mathrm{C}] \mathrm{PBB} 3}\end{array}$ & $\begin{array}{l}\text { Increased } \\
\text { retention }\end{array}$ & $\begin{array}{l}\text { Frontal cortex, temporal cortex, parietal cortex and } \\
\text { hippocampus/ entorhinal region }\end{array}$ \\
\hline Glucose metabolism & {$[18 \mathrm{~F}] \mathrm{FDG}$} & $\begin{array}{l}\text { Low } \\
\text { uptake }\end{array}$ & $\begin{array}{l}\text { Parietotemporal association cortices, medial } \\
\text { temporal cortex, posterior cingulate and frontal } \\
\text { cortex (at later stages) }\end{array}$ \\
\hline Neuroinflammation & $\begin{array}{l}{[11 \mathrm{C}] \mathrm{PK} 11195} \\
{[11 \mathrm{C}] \mathrm{DAA} 1106} \\
\text { [18F]FEDAA1106 } \\
\text { [11C]AC5216 } \\
\text { [11C]A836339 } \\
\text { [11C]L-deprenyl }\end{array}$ & $\begin{array}{l}\text { Increased } \\
\text { retention }\end{array}$ & Widespread retention within the whole brain \\
\hline
\end{tabular}

\subsection{New detection}

\section{- Nanotechnology and biosensor}

Nowadays, the main focus of AD detection is focused on beta-amyloid oligomers $(\mathrm{A} \beta \mathrm{O})$ and the use of nanoparticles (NP) brings up the sensitivity and the precision of early AD detection. NP exhibits a wide range of functions, given its various application with ligands and the ability to cross very impermeable blood brain barriers (BBB). One main purpose of NP is to detect the formation and site of $\mathrm{A} \beta \mathrm{O}$ plaque in the brain. Another main purpose is to detect the concentration of $\mathrm{A} \beta \mathrm{O}$ in $\mathrm{CSF}$, using $\mathrm{A} \beta \mathrm{O}$ antibody-conjugated gold NP [24]. In order to enhance detection performance, $\mathrm{Li}$ and colleague developed a reusable biosensor using $A \beta$ antibody's conjugation with magnetic nitrogen-doped graphene (MNG) on the biosensor to detect AD-related $\mathrm{A} \beta$ aggregation. It saves up the detection time and also enhance the precision [25].

- Development of biomarker

From DNA whole genome sequencing of serum mononuclear, Di Francesco and colleagues found out the significant elevation of global DNA methylation in people with LOAD [26]. This study establishes the possibility of using peripheral blood as a biomarker for AD. Unfortunately, using a new ultrasensitive single molecule array (Simoa) antibody-based approach on plasma $A \beta$ and total plasma tau are inconclusive, suggesting the necessity to narrow down the target of detection. New studies show that peripheral blood test on phosphorylated tau 181 (Ptau 181) might also be the biomarker for $\mathrm{AD}$, making the diagnosis and prognosis less progressive [27] \& [28]. According to the article, plasma P-tau 181 assay almost have the same AD differentiation ability compared with two standard diagnostic approaches, A $\beta$-PET and CSF pTau181. More importantly, p-tau 181 demonstrates the possibility of prevention or advancement of diagnosis, given the fact that its cognition decline can be predicted over two years of following up.

Besides, it is important to distinguish Mild cognitive impairments (MCI) and $\mathrm{AD}$ during the diagnose. $\mathrm{MCI}$ is in the middle of normal aging cognitive process, and the onset of $\mathrm{AD}$. $\mathrm{AD}$ will progress from memory loss, financial management difficulties to loss of activities of daily living (ADLs), whereas MCI will not be likely to deteriorate and has the potential for irreversibility. However, what makes the diagnoss between AD and MCI ambiguous is their numerous overlapping symptoms, 
indicating physicians' disagreement and misdiagnoses. A new research of Xie [29] aimed to solve this problem. They studied BDNF promoter methylation and tag single nucleotide polymorphisms (tag SNPs) on amnestic MCI and $\mathrm{AD}$ patients. The result shows that there are different pieces of tag SNP associated with aMCI and AD, making diagnostic testing of the conversion from aMCI to AD possible.

\section{Medication}

\subsection{Traditional Drug}

It is impossible to cure the AD. Current medication for AD mainly aims to slow down the progression like most chronic diseases. There are three major mechanisms: Cholinesterase inhibitors to lessen memory loss, excessive glutamate blocker to mitigate cell death and injuries, and psychiatric medications to alleviate mentalbehavioral abnormality[30]. Below attached FDAapproved drug list for AD.

Acetylcholinesterase (AChE), existing in the synaptic cleft, has the function of degenerating excessive acetylcholine. Normally, cholinesterase works when acetylcholine's job as a neurotransmitter is done from the post-synaptic receptor. Whereas in patients with $\mathrm{AD}$, cholinesterase's usual hydrolysis process makes the signaling between neurons even harder, aggravating the brain inactivity caused by $\mathrm{A} \beta$ plaque cascade. Therefore, cholinesterase inhibitors (ChEI) are designated for AD treatment with the current FDA-approved drugs including Donepezil, Rivastigmine and Galantamine. Though ChEI listed above are predominant $\mathrm{AD}$ drugs, its management on the loss of mental abilities on the short-term has been mild, and its enhancement on mood disorder, ACL, as well as the quality of life have been inconclusive [31] The inefficacy of those traditional drugs thrusts the development of new ChEI, including physostigmine derivatives, naturally-derived inhibitors, and synthetic analogue [32]. However, studies on physostigmine derivatives' preclinical or clinical application, naturallyderived inhibitors' toxicity, and synthetic analogues' BBB permeability, are underdeveloped.

Glutamate is the most abundant excitatory neurotransmitter. AD's progression levels up the extrasynaptic glutamate in response to glutamate reuptake impediment. The excessive glutamate binds to NMDA receptors on the post-synaptic membrane with overstimulation, perturbing normal learning and memorizing process. Thus, NMDA antagonist, Memantine, is geared towards excitotoxicity. Despite the pervasive use of Menmantine, studies have shown the minimal effect that it has on arresting AD progression [33].

The use of Memantine is targeted to people with moderate-to-severe $\mathrm{AD}$, whereas $\mathrm{ChEI}$ is targeted to people with mild-to-moderate AD. What is more, studies show that a combination of $\mathrm{ChEI}$ and Memantine has the additional ameliorating ability on neurobehavioral symptoms. Therefore, combination therapy using Namzaric was approved by FDA [34].The limitation of single-target ChEIs and NMDA antagonists prompts researches for multifunctional CTs and medications aiming at the origin of $\mathrm{AD}$ pathogenesis.

\subsection{Combination therapy}

Monotherapy towards $\mathrm{AD}$ has its limitation on the conflicts between tolerability and efficacy, as well as the monotonous targets. Whereas CT may possibly contribute to a multifactual and synergistic treatment. Each medication in CT has a therapeutic effect on different pathogeneses of $\mathrm{AD}$ including amyloid pathology, tau pathology, neurotrophic deficits, excitotoxicity, metabolic alterations and oxidative stress. According to the detailed review from [34], Table 6 for currently researched CTs with its effect and progress is concluded.

Table6. AD potential combination therapy and its progress

\begin{tabular}{|l|l|l|}
\hline Generic name & Effect, what is better than monotherapy & Progress \\
\hline $\begin{array}{l}\text { Galantamine and } \\
\text { Memantine }\end{array}$ & $\begin{array}{l}\text { Inhibit NMDAR overaction and inhibit AChE } \\
\text { by activating nicotinic Ach receptors and } \\
\text { slowing down glutamine excitotoxic cascade. }\end{array}$ & $\begin{array}{l}\text { The production of heterodimer of } \\
\text { galantamine and memantine }\end{array}$ \\
\hline $\begin{array}{l}\text { Memantine and } \\
\text { Nitroglycerin } \\
\text { Nitromemantine) }\end{array}$ & $\begin{array}{l}\text { Recover synaptic and dendritic density and } \\
\text { enhance location -novelty recognition ability }\end{array}$ & $\begin{array}{l}\text { In vivo triple transgenic AD mice } \\
\text { model with nitromemantine }\end{array}$ \\
\hline Donepezil and Clioquinol & $\begin{array}{l}\text { Subdue beta-amyloid aggregation by using } \\
\text { clioquinol as metal-chelating therapy towards } \\
\text { zinc and copper growth in AD. }\end{array}$ & $\begin{array}{l}\text { In vitro of hybrid molecule 7-((4-(2- } \\
\text { methoxybenzyl) piperazin-1-yl) } \\
\text { methyl)-8-hydroxyquinoline with } \\
\text { conservation of pharmacokinetic } \\
\text { properties and without overly rising } \\
\text { molecular weight }\end{array}$ \\
\hline $\begin{array}{l}\text { Rivastigmine and } \\
\text { Lasagiline: }\end{array}$ & $\begin{array}{l}\text { Reversibly impede choline decomposition } \\
\text { and irreversibly discourage MAO-B's } \\
\text { catabolism of CNS amine. Promote motor } \\
\text { and memory function and decrease APP } \\
\text { concentration. }\end{array}$ & In vivo mice with Ladostigil \\
\hline
\end{tabular}




\begin{tabular}{|c|c|c|}
\hline $\begin{array}{l}\text { VK-28 and } \\
\text { Propargylamine } \\
\text { M-30 }\end{array}$ & $\begin{array}{l}\text { VK-28's metal-chelation effect } \\
\text { propargylamine's effect for neuropathway } \\
\text { protection }\end{array}$ & M-30 \\
\hline PBT2 and ChEIs & $\begin{array}{l}\text { Additionally, manage protein-metal toxicity } \\
\text { by ionophore PBT2's ability to transport zinc } \\
\text { and copper out of cells }\end{array}$ & Early phase 2 clinical trial \\
\hline $\begin{array}{l}\text { Noradrenaline reuptake } \\
\text { inhibitors (Atomoxetine) } \\
\text { and ChEIs/ NMDAR } \\
\text { antagonists }\end{array}$ & $\begin{array}{l}\text { Elevate level of declined norepinephrine level } \\
\text { in } \mathrm{AD} \text { patients for more active sympathetic } \\
\text { response. }\end{array}$ & $\begin{array}{l}\text { Only proven efficacy in patients with } \\
\text { moderate-to-severe AD }\end{array}$ \\
\hline $\begin{array}{l}\text { Anti-tau agents } \\
\text { (Valproate) }\end{array}$ & $\begin{array}{l}\text { Inhibit tau phosphorylation and reduce } \\
\text { aggregation of tau. }\end{array}$ & $\begin{array}{l}\text { No shown cognitive improvement } \\
\text { with toxic side effect in Phase III } \\
\text { clinical trial }\end{array}$ \\
\hline Neurotrophic agents & $\begin{array}{l}\text { Bring up the neurotrophic signaling decline of } \\
\text { IGF-1, BDNF and nerve growth factor } \\
\text { downregulation correlated with AD neural } \\
\text { degeneration. }\end{array}$ & $\begin{array}{l}\text { No shown efficacy with Xaliproden } \\
\text { and MK-677. } \\
\text { CT of Donepezil and Cerebrolysin } \\
\text { exhibit synergistic effect compared to } \\
\text { donepezil monotherapy }\end{array}$ \\
\hline Antioxidative factors & $\begin{array}{l}\text { Resolve the oxidative damages associated } \\
\text { with AD progression }\end{array}$ & $\begin{array}{l}\text { Vitamin E, group B vitamin \& omeg- } \\
3 \text { fatty acid }\end{array}$ \\
\hline $\begin{array}{l}\text { Anti-inflammatory drugs } \\
\text { Ibuprofen and celecoxib } \\
\text { Refecoxib and naproxen, }\end{array}$ & $\begin{array}{l}\text { Resolve the inflammation caused by } \\
\text { increased inflammatory signal due to AD } \\
\text { mechanism }\end{array}$ & $\begin{array}{l}\text { No observed clinical efficacy of } \\
\text { combination of both ibuprofen and } \\
\text { celecoxib as well as Refecoxib and } \\
\text { naproxen } \\
\text { in Phase III studies }\end{array}$ \\
\hline $\begin{array}{l}\text { Antidiabetic drugs } \\
\text { Insulin }\end{array}$ & $\begin{array}{l}\text { Slow down cognitive decline in patients with } \\
\text { both AD and DM II, given the comorbidity of } \\
\text { AD and DMII }\end{array}$ & Additive effect \\
\hline
\end{tabular}

\subsection{New medications depending on epigenetics}

Folic acid and vitamin group B are DNA methylation activator with therapeutic effect towards $A D$, which is discussed below on Health promotion.

- Histone deacetylase inhibitors

According to [11] Qazi, the most widely studied are trichostatin A (TSA), valproic acid (VPA), vorinostat (SAHA), and sodium 4-phenylbutyrate (4-PBA) used for
pan-HDAC inhibition, and nicotinamide specific for class III HDAC inhibition. However, only VPA and nicotinamide transmit from animal models to clinical trials [35]. The effects of those five HDACis are summarized in Table 7 below according to Qazi [11], and all the potential epigenetic treatment targeting DNA methylation and histone modification are copied from Cacabelos and Teijido.

Table7. Major HDAC's Mechanism and Current experimental phase.

\begin{tabular}{|l|l|l|l|}
\hline Name & Effect & Mechanism & Model \\
\hline VPA & $\begin{array}{l}\text { Relieve contextual } \\
\text { memory deficit }\end{array}$ & Reduce A $\beta$ production & AD transgenic mouse \\
\hline SAHA & $\begin{array}{l}\text { Reverse spatial learning } \\
\text { and memory deficits }\end{array}$ & $\begin{array}{l}\text { Decrease A } \beta \text { production and } \\
\text { au } \\
\text { phosphorylation }\end{array}$ & $\begin{array}{l}\text { Tg2576 AD } \\
\text { mouse mode }\end{array}$ \\
\hline TSA & $\begin{array}{l}\text { Enhancement of learning } \\
\text { and memory }\end{array}$ & $\begin{array}{l}\text { Increase H4K12 acetylation } \\
\text { Induce the expression of } \\
\text { clustering } \\
\text { Inhibit HDAC6 }\end{array}$ & $\begin{array}{l}\text { Mouse model } \\
\text { ASTROCYTE CELL } \\
\text { APPswe/PS1dE9 mouse } \\
\text { model }\end{array}$ \\
\hline Nicotinamide & $\begin{array}{l}\text { Retter signaling } \\
\text { Increase microtubule } \\
\text { stability }\end{array}$ & $\begin{array}{l}\text { Induce BDNF } \\
\text { increase acetylation of alpha- } \\
\text { tubulin and MAP2c }\end{array}$ & Nouron-2a cell \\
\hline
\end{tabular}




\section{AD Care guidance}

Thorough and evidence-based $\mathrm{AD}$ care guidance is essential for bringing up $\mathrm{AD}$ patients' quality of life, alleviating its burden on the healthcare system and on patient families. Most people with AD are not hospitalized in a clinical setting; the majority of their time is spent at home or assisted living facilities. Juxtaposing with diagnosis and medication, patient care is supposed to receive prodigious attention but in fact in often ignored. In order to compensate the loss, care models have been developed to enhance dementia care coordination, especially about $\mathrm{AD}$, and many aspects have been shown improvement like the utilization of community services [36]. However, this subject is still very highly undeveloped. Therefore, using nurses as a central role, healthcare providers (HCP) need to corporate with family members and the community aiming to foster caring guidance of better quality.

AD's care and therapies are altered depending on the patients' AD stage and prognosis. It is commonly known that orientation therapy should be applied to patients in the early stage, whereas validation therapy to be used in moderate and severs stages. For orientation therapy, family members or HCP should dedicate to correct and solve patients' confusion and misunderstanding and make sure that they adhere to every day's schedule. While in validation therapy, the target should be put on purely communication, and caregivers should reinforce what patients say. Orientation therapy and validation therapy are solely the framework and basis of AD care. In order to promote $\mathrm{AD}$ care to a more comprehensive level, the use of health resource, transdisciplinary teamwork, education on advanced care planning, and more evidence-based researches are required.

The promotion of cognition for mental health and its resources is crucial. Compared to physical health, mental health is not easy to recognize. However, studies show that late-life depression may be a prodromal feature of dementia, and the comorbidity between dementia and depression exists [37]. Therefore, it is essential for nurses to educate patients and their family members to pay attention to neuropsychiatric symptoms (NPS) in daily life and also for HCP to focus on NPS during prognosis and treatment. The unidentified and untreated NPS in clinical settings decrease the rate for dementia detection, indirectly leads to delayed diagnosis for AD. According to this study [38] , 45 measures published have adequate psychometric properties to identify people with dementia; nurses could communicate with nursing leaders for suggestions of a more appropriate and modified version of the assessment tool.

The concept of work delegation within transdisciplinary teamwork is indispensable. Many unlicensed community health workers (CHW) are capable of communicating between patients and healthcare facilities by giving an appropriate referral. According to a study, CHW after appropriate AD and dementia knowledge training can effectively give a diagnosis of dementia depending on clinical dementia rating compared to physicians' diagnosis in the community-dwelling
Korean American community [39]. By delegating work to and communicate with qualified $\mathrm{CHW}$, it can reduce the workload of HCP - one important barrier for the incompetency of $\mathrm{AD}$ care coordination and bring the most out of CHW's potential for social responsibility.

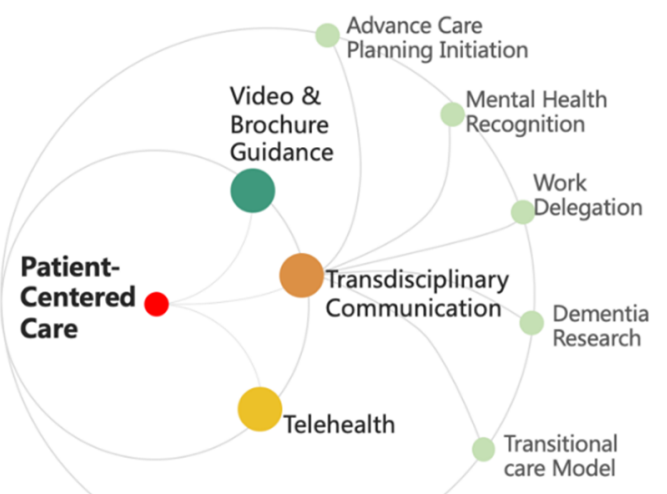

Fig1. patient-centered care model

Researches on "hands-on" communication with patients with dementia, especially AD is needed. There is an imbalance in patients' quality of dementia care and HCP's efforts. According to a study, HCP in chronic health care and palliative care field have excellent disease knowledge $(90 \%)$, but low job satisfaction and burnout are still a common phenomenon, which is not good at improving dementia care coordination in the long run [40]. Therefore, researches focusing on patient-centered care, like managing behaviors non-pharmacologically, enhancing patient safety, coping with care challenges, and involving patients in activities, are of high demand in order to modify the care and bring the contradiction between high knowledge scores and feeling of frustration [40].

An initiation of adequate education of advance care planning (ACP) is necessary. ACP is the process where patients determine what they want when it comes to endof-life care. Studies show that family members' inaccuracy $(35 \%)$ of predicting patient's ACP [41]. ACP is so negative and heartbroken that family members try to avoid communication on death. Dening suggested that HCP, especially nurses, should play an important role in assisting patients with ACP by emphasizing the importance of ACP, educating patients about certain checkpoints that they can initiate ACP, and so on.

Patients with AD might endure an elongated period of AD progression, starting from as early as people's 30 s. Patients' quality of life has a direct influence on the exacerbation level of $\mathrm{AD}$. An overarching $\mathrm{AD}$ care system will benefit the patients, their families, and HCPs as Figure 1 shows.

\section{Health Promotion and Prevention}

The natural delay of $\mathrm{AD}$ onset and palliation of $\mathrm{AD}$ progression can be accomplished by health promotions. What is more, by complying with proper dietary and lifestyle changes, the prevention might also be possible. According to Healthy People 2030, nutrition, physical 
activity, and obesity are leading health indicators (LHIs), which are also risk factors for $\mathrm{AD}$. Though simple lifestyle regulations, such as exercise, calorie restriction, and adequate glucose intake, are the macroscopic goals, there are many scientific studies proving the connection between biomolecular level and lifestyle changes for people with $\mathrm{AD}$.

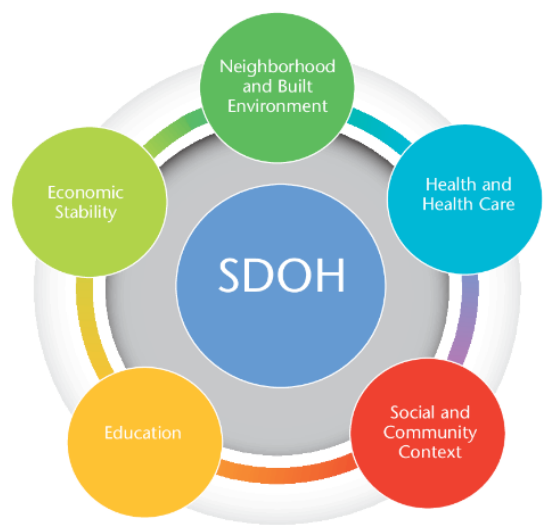

Fig2. SDOH of Health People 2030

Calorie restriction, including limited glucose, cholesterol and fatty acid intake, is beneficial to human entire body system and prevents AD pathology. Expression of longevity gene is restricted by cholesterol, and fatty acids, which will slow down mitochondrial function and increase oxidative stress. On the contrary, healthy mitochondrial processing and limited oxidative stress can promote fine neurogenesis and synaptic plasticity in the brain. What is more, a decrease in calorie intake reduces IGF-1 (insulin-like growth hormones) and rises AMPK (AMP activated protein kinase), both of which decrease the production of mTOR. In this way, a proper drop of mTOR for adults will help with cell repair and maintenance [42]. It is essential to remain the clearance of brain metabolite and to restore the ability towards neuronal damage, which will alleviate AD progression. Furthermore, the more glucose intake leads to less BDNF, which also leads to the damage to the brain and weakens the capacity for brain reserve [2]. Thus, appropriate glucose intake will help with the function of nerve cells and indirectly prevent AD's deterioration.

According to AHA, the females' intake of added sugar should not exceed $25 \mathrm{~g}$, and males should not exceed $37.5 \mathrm{~g}$. Many fruits rich in minerals and vitamins are of high sugar levels, such as apples, mangos, cherries, bananas, oranges, grapes, eras and so on [43]. Many commodities have "healthy" label on it, whose sugar level is also high such as low-fat yogurt, fruit juice, granola bar, and so on. It is highly recommended to restrict calories by checking daily intake and serving size in order to protect the brain and AD pathology.

Folic acid and vitamin group B intake activate DNA methylation beneficial to alleviating AD progression. According to Liu [15], folic acid exhibits dose-dependent function to elevate DNMT activity and cell viability in rat primary neurons and the mouse HT-22 cells exposing to $\mathrm{A} \beta \mathrm{O}$ - an obvious hallmark of $\mathrm{AD}$. What is more, using folic supplements in both HT-22 cells and APP/PS1 cells can upregulate DNA methylation in both APP promoter and presenilin 1 (PS1) promoter at different $\mathrm{CpG}$ sites and bring up the methylation potential (SAM: SAH). What is more, the existence of vitamin $\mathrm{B}_{6}$ and $\mathrm{B}_{12}$ are necessary for the complex process of forming methyl donor for DNA methylation [44]. Overall, the linkage between folic acid and vitamin group $\mathrm{B}$, and its impact on DNA methylation for certain AD modifying genes promote the folic acid and vitamin group B intake from either supplements or nutrients-enriched food.

\section{Indirect influence by other body parts}

Health conditions in the heart can indirectly regulate the brain's function. Most of the time, atrial fibrillation (AF) is subclinical/asymptomatic, and its frequent manifestation is stroke. Patients undergo AF have a higher risk for stroke, which contributes to one-third of ischemic stroke [45]. Ischemic stroke damages the vessels aligning on blood-brain barriers and trigger continuous inflammation, which all fasten AD prognosis. Hence, bringing up the health of hearts by exercise and diet restriction can lessen atherosclerosis induced myocardial infarction and potentially lower the risk for AD.

A balance of gut microbiome in our digestive system is significant for brain function [46]. Studies show that gut microbiome alterations may link to AD pathology and the potential that healthy diet change may lower the risk for $\mathrm{AD}$. It is found that $\mathrm{AD}$ patients have decreased phylum Firmicutes and increased phylum Bacteroidetes, as well as the association between those gut microbiome changes and type II diabetes. What is more, increased phylum Bacteroidetes also promotes amyloid deposition and tau pathology because of its major lipopolysaccharide (LPS) component. Therefore, amending the gut microbiome by eating various healthy food and appropriate supplements may increase the development of insulin resistance, therefore, lower the risk for AD and reduce LPS's reaction with AD's pathology.

The purpose of health promotion is to use the attention paid on daily activities to slow down or prevent the occurrence of AD. This not only will decrease AD population, but also reduce the medical expenditure. The total payment for AD in 2017 is $\$ 259$ billion, $67.5 \%$ out of which was covered by Medicare and Medicaid. By 2050 the cost for AD is predicted to reach $\$ 1.1$ trillion [47]. Therefore, appropriate health promotions can benefit people worldwide and also relieve some of the healthcare system's pressure.

\section{Conclusion}

Over around 30 years, from the traditional hypothesis, to the introduction of epigenetics, to the adaptation of diagnosis and medications, to the emphases of $\mathrm{AD}$ care and health promotion, many aspects of $\mathrm{AD}$ are updated constantly. Unfortunately, the possibility of curing AD, like most chronic illness still cannot be foreseen. Many studies based on gene mutation and classic hypotheses have met unprecedented bottleneck.

There are outliers of general recognition towards APOE polymorphism. Gene APOE4 mutation with 
disparate cholesterol metabolic levels is widely known to be associated with AD. PSEN1 gene is an indication of early-onset $\mathrm{AD}$, also known as $\mathrm{DIAD}$, with an average onset of Alzheimer's at age 49. A new case report published in 2019 shows a counterintuitive effect when 2 APOE3 alleles and PSEN1 mutation carriers exist in one Colombian participant. Though this female has this autosomal dominant PSEN1 gene, she doesn't have earlyonset $\mathrm{AD}$. According to the brain images, this participant's cerebral metabolic rate for glucose is higher than people with the PSEN1 mutation gene only. This new case report expands the possibility of different gene's interaction and its contribution to AD.

Besides, as a 25-year-old hypothesis, the cytotoxicity of senile plaque influences the synaptic activity and therefore lead to $\mathrm{AD}$ symptoms. However, many researches question the direct relation between $A \beta$ and AD. In animal trial, a single $A \beta 42$-overexpressing gene does not induce cognitive ability, and the efficacy of $\mathrm{A} \beta$-targeted immunotherapy is low in AD mouse model. Moreover, in imaging, there is an obscure diagnostic line between $\mathrm{AD}$ and non- $\mathrm{AD}$ on the brain's $\mathrm{A} \beta$ accumulation. Kametani and Hasegawa also elucidate the superiority of APP's C-terminal fragments mechanism and tau-phosphorylation. The potential tocity of Cterminal fragments, including p3, AICD, C99, and C83 is neglected. Except for $\mathrm{A} \beta$ accumulation, C-terminal fragments accumulation can also be the negative effect of PS1 and APP mutations and can even be invigorated by $\gamma$-secretase inhibitor as therapy.

What is more, tau-phosphorylation is discovered to play a more imperative role in neurodegenerative diseases, like $\mathrm{AD}$, than $\mathrm{A} \beta$ accumulation. About tau's own appliance, tau's propagation, according to Braak's stage system, correlates highly with the onset and progression of AD symptoms. Not to mention tau tanglements might possess the potential of intercellular and inter-region selfconversion. What is more, TREM2-APOE4 pathway is suggested to induce the progression of tauopathy. APOE4 mutation slows down neuronal repair and triggering receptor expressed on myeloid cells (TREM2) promote secondary inflammation due to microglial phagocytosis, both of which are huge risk factors for tau's impact on brain. Furthermore, APP might function as a receptor of abnormal tau fibrils. Though APP and tau's own independency of initiation cannot be ruled out, it suggests an $\mathrm{AD}$ hypothesis without the influence of $\mathrm{A} \beta$ accumulation.

As discussed in this review, traditional ideas are the basis of many advancements, and novel trial and suggestions are potential for pioneering break. This review paper summarizes the contribution of epigenetics to $\mathrm{AD}$ mechanism, diagnosis, and medication and also highlights the importance of what is outside of the hospital - AD care and health promotion

\section{References}

1. Alzheimer's Association. [Retrieved from https://www.alz.org/alzheimers-dementia/factsfigures]
2. Kuller, L. H., O. L. Lopez, R. H. Mackey, C. Rosano, D. Edmundowicz, J. T. Becker \& A. B. Newman (2016) Subclinical Cardiovascular Disease and Death, Dementia, and Coronary Heart Disease in Patients 80+Years. Journal of the American College of Cardiology, 67, 1013-1022.

3. Querfurth, H. W. \& F. M. LaFerla (2010) MECHANISMS OF DISEASE Alzheimer's Disease. New England Journal of Medicine, 362, 329-344.

4. Geriatric Depression Scale. [Retrieved from https:/www.apa.org/pi/about/publications/caregiver s/practice-settings/assessment/tools/geriatricdepression]

5. Kametani, F. \& M. Hasegawa (2018) Reconsideration of amyloid hypothesis and tau hypothesis in Alzheimer's disease. Frontiers in neuroscience, 12, 25.

6. Mohandas, E., V. Rajmohan \& B. Raghunath (2009) Neurobiology of Alzheimer's disease. Indian journal of psychiatry, 51, 55.

7. Wiseman, F. K., L. J. Pulford, C. Barkus, F. Liao, E. Portelius, R. Webb, L. Chávez-Gutiérrez, K. Cleverley, S. Noy \& O. Sheppard (2018) Trisomy of human chromosome 21 enhances amyloid- $\beta$ deposition independently of an extra copy of APP. Brain, 141, 2457-2474.

8. Liu, X. L., B. Jiao \& L. Shen (2018) The Epigenetics of Alzheimer's Disease: Factors and Therapeutic Implications. Frontiers in Genetics, 9.

9. D’Urso, A. \& J. H. Brickner (2014) Mechanisms of epigenetic memory. Trends in genetics, 30, 230-236.

10. Lacal, I. \& R. Ventura (2018) Epigenetic inheritance: concepts, mechanisms and perspectives. Frontiers in molecular neuroscience, 11, 292.

11. Qazi, T. J., Z. Quan, A. Mir \& H. Qing (2018) Epigenetics in Alzheimer's disease: perspective of DNA methylation. Molecular Neurobiology, 55, 1026-1044.

12. Wei, X., L. Zhang \& Y. Zeng (2020) DNA methylation in Alzheimer's disease: in brain and peripheral blood. Mechanisms of Ageing and Development, 111319.

13. Yokoyama, A. S., J. C. Rutledge \& V. Medici (2017) DNA methylation alterations in Alzheimer's disease. Environmental epigenetics, 3.

14. Li, Y. Y., T. Chen, Y. Wan \& S. q. Xu (2012) Lead exposure in pheochromocytoma cells induces persistent changes in amyloid precursor protein gene methylation patterns. Environmental toxicology, 27, 495-502.

15. Liu, H., W. Li, S. Zhao, X. Zhang, M. Zhang, Y. Xiao, J. X. Wilson \& G. Huang (2016) Folic acid attenuates the effects of amyloid $\beta$ oligomers on DNA methylation in neuronal cells. European journal of nutrition, 55, 1849-1862.

16. Mano, T., K. Nagata, T. Nonaka, A. Tarutani, T. Imamura, T. Hashimoto, T. Bannai, K. Koshi-Mano, T. Tsuchida, R. Ohtomo, J. Takahashi-Fujigasaki, S. 
Yamashita, Y. Ohyagi, R. Yamasaki, S. Tsuji, A. Tamaoka, T. Ikeuchi, T. C. Saido, T. Iwatsubo, T. Ushijima, S. Murayama, M. Hasegawa \& A. Iwata (2017) Neuron-specific methylome analysis reveals epigenetic regulation and tau-related dysfunction of BRCA1 in Alzheimer's disease. Proceedings of the National Academy of Sciences of the United States of America, 114, E9645-E9654.

17. Wu, Y., F. Hou, X. Wang, Q. Kong, X. Han \& B. Bai (2016) Aberrant expression of histone deacetylases 4 in cognitive disorders: molecular mechanisms and a potential target. Frontiers in Molecular Neuroscience, 9, 114.

18. Delay, C., W. Mandemakers \& S. S. Hébert (2012) MicroRNAs in Alzheimer's disease. Neurobiology of disease, 46, 285-290.

19. Meyer, K., H. M. Feldman, T. Lu, D. Drake, E. T. Lim, K. H. Ling, N. A. Bishop, Y. Pan, J. Seo, Y. T. Lin, S. C. Su, G. M. Church, L. H. Tsai \& B. A. Yankner (2019) REST and Neural Gene Network Dysregulation in iPSC Models of Alzheimer's Disease. Cell Reports, 26, 1112-+.

20. Simmons, B. B., B. Hartmann \& D. DeJoseph (2011) Evaluation of suspected dementia. American family physician, 84, 895-902.

21. Costa, M. V., M. F. Diniz, K. K. Nascimento, K. S. Pereira, N. S. Dias, L. F. Malloy-Diniz \& B. S. Diniz (2016) Accuracy of three depression screening scales to diagnose major depressive episodes in older adults without neurocognitive disorders. Brazilian Journal of Psychiatry, 38, 154-156.

22. Alzheimer Disease (2019) [retrieved from: https://labtestsonline.org/conditions/alzheimerdisease]

23. Schilling, L. P., E. R. Zimmer, M. Shin, A. Leuzy, T. A. Pascoal, A. L. Benedet, W. V. Borelli, A. Palmini, S. Gauthier \& P. Rosa-Neto (2016) Imaging Alzheimer's disease pathophysiology with PET. Dementia \& Neuropsychologia, 10, 79-90.

24. Hajipour, M. J., M. R. Santoso, F. Rezaee, H. Aghaverdi, M. Mahmoudi \& G. Perry (2017) Advances in alzheimer's diagnosis and therapy: The implications of nanotechnology. Trends in biotechnology, 35, 937-953.

25. Li, S.-S., C.-W. Lin, K.-C. Wei, C.-Y. Huang, P.-H. Hsu, H.-L. Liu, Y.-J. Lu, S.-C. Lin, H.-W. Yang \& C.-C. M. Ma (2016) Non-invasive screening for early Alzheimer's disease diagnosis by a sensitively immunomagnetic biosensor. Scientific reports, 6, 111.

26. Di Francesco, A., B. Arosio, A. Falconi, M. V. M. Di Bonaventura, M. Karimi, D. Mari, M. Casati, M. Maccarrone \& C. D'Addario (2015) Global changes in DNA methylation in Alzheimer's disease peripheral blood mononuclear cells. Brain Behavior and Immunity, 45, 139-144.

27. Janelidze, S., N. Mattsson, S. Palmqvist, R. Smith, T. G. Beach, G. E. Serrano, X. Chai, N. K. Proctor, U. Eichenlaub \& H. Zetterberg (2020) Plasma P-tau181 in Alzheimer's disease: relationship to other biomarkers, differential diagnosis, neuropathology and longitudinal progression to Alzheimer's dementia. Nature Medicine, 26, 379-386.

28. Thijssen, E. H., R. La Joie, A. Wolf, A. Strom, P. Wang, L. Iaccarino, V. Bourakova, Y. Cobigo, H. Heuer, S. Spina, L. VandeVrede, X. Y. Chai, N. K. Proctor, D. C. Airey, S. Shcherbinin, C. D. Evans, J. R. Sims, H. Zetterberg, K. Blennow, A. M. Karydas, C. E. Teunissen, J. H. Kramer, L. T. Grinberg, W. W. Seeley, H. Rosen, B. F. Boeve, B. L. Miller, G. D. Rabinovici, J. L. Dage, J. C. Rojas, A. L. Boxer \& F. Advancing Res Treatment Diagnostic value of plasma phosphorylated tau181 in Alzheimer's disease and frontotemporal lobar degeneration. Nature Medicine, 25.

29. Xie, B., Z. C. Liu, W. X. Liu, L. Jiang, R. Zhang, D. S. Cui, Q. F. Zhang \& S. J. Xu (2017) DNA Methylation and Tag SNPs of the BDNF Gene in Conversion of Amnestic Mild Cognitive Impairment into Alzheimer's Disease: A Cross-Sectional Cohort Study. Journal of Alzheimers Disease, 58, 263-274.

30. Kandimalla, R. \& P. H. Reddy (2017) Therapeutics of neurotransmitters in Alzheimer's disease. Journal of Alzheimer's Disease, 57, 1049-1069.

31. InformedHealth. Org (2019). [Retrieved from www.ncbi.nlm.nih.gov/books/NBK279358/.]

32. Sharma, K. (2019) Cholinesterase inhibitors as Alzheimer's therapeutics. Molecular medicine reports, 20, 1479-1487.

33. McShane, R., M. J. Westby, E. Roberts, N. Minakaran, L. Schneider, L. E. Farrimond, N. Maayan, J. Ware \& J. Debarros (2019) Memantine for dementia. Cochrane Database of Systematic Reviews.

34. Kabir, M., M. Uddin, A. A. Mamun, P. Jeandet, L. Aleya, R. A. Mansouri, G. M. Ashraf, B. Mathew, M. N. Bin-Jumah \& M. M. Abdel-Daim (2020) Combination drug therapy for the management of Alzheimer's disease. International Journal of Molecular Sciences, 21, 3272.

35. Cacabelos, R. \& O. Teijido. 2018. Epigenetic drug discovery for Alzheimer's disease. In Epigenetics of aging and longevity, 453-495. Elsevier.

36. Hughes, S., Lepore, M., Wiener, J., \& Gould, E. (2017). Research on Care Coordination for People with Dementia and Family Caregivers. [Retrieved from https://aspe.hhs.gov/basic-report/research-carecoordination-people-dementia-and-familycaregivers]

37. Kverno, K. S. \& R. Velez (2018) Comorbid Dementia and Depression: The Case for Integrated Care. JnpJournal for Nurse Practitioners, 14, 196-201.

38. Gitlin, L. N., K. A. Marx, I. H. Stanley, B. R. Hansen \& K. S. Van Haitsma (2014) Assessing neuropsychiatric symptoms in people with dementia: a systematic review of measures. International psychogeriatrics/IPA, 26, 1805. 
39. Han, H.-R., S.-Y. Park, H. Song, M. Kim, K. B. Kim \& H. B. Lee (2013) Feasibility and Validity of Dementia Assessment by Trained Community Health Workers Based on Clinical Dementia Rating. Journal of the American Geriatrics Society, 61, 1141-1145.

40. Marx, K. A., I. H. Stanley, K. Van Haitsma, J. Moody, D. Alonzi, B. R. Hansen \& L. N. Gitlin (2014) Knowing Versus Doing Education and Training Needs of Staff in a Chronic Care Hospital Unit for Individuals With Dementia. Journal of Gerontological Nursing, 40, 26-34.

41. Harrison Dening, K., C. Scates, G. McGill \& K. DeVries (2019) A training needs analysis of admiral nurses to facilitate advance care planning in dementia. Palliative Care: Research and Treatment, 12, 1178224219850183.

42. North, B. J. \& D. A. Sinclair (2012) The Intersection Between Aging and Cardiovascular Disease. Circulation Research, 110, 1097-1108.

43. Whitbread, D., (2020) Top 15 Fruits Highest in Sugar, [retrieved from (www.myfooddata.com/articles/high-sugarfruits.php).]

44. Plasek, J. \& M. Taborsky (2019) Subclinical atrial fibrillation - what is the risk of stroke? Biomedical Papers-Olomouc, 163, 107-113.

45. Vogt, N. M., R. L. Kerby, K. A. Dill-McFarland, S. J. Harding, A. P. Merluzzi, S. C. Johnson, C. M. Carlsson, S. Asthana, H. Zetterberg, K. Blennow, B. B. Bendlin \& F. E. Rey (2017) Gut microbiome alterations in Alzheimer's disease. Scientific Reports, $7,11$.

46. Naqvi, E. (2017). Alzheimer's Disease Statistics. Retrieved from https://alzheimersnewstoday.com/alzheimersdisease-statistics/

47. Arboleda-Velasquez, J. F., F. Lopera, M. O'Hare, S. Delgado-Tirado, C. Marino, N. Chmielewska, K. L. Saez-Torres, D. Amarnani, A. P. Schultz, R. A. Sperling, D. Leyton-Cifuentes, K. W. Chen, A. Baena, D. Aguillon, S. Rios-Romenets, M. Giraldo, E. Guzman-Velez, D. J. Norton, E. Pardilla-Delgado, A. Artola, J. S. Sanchez, J. Acosta-Uribe, M. Lalli, K. S. Kosik, M. J. Huentelman, H. Zetterberg, K. Blennow, R. A. Reiman, J. Luo, Y. H. Chen, P. Thiyyagura, Y. Su, G. R. Jun, M. Naymik, X. W. Gai, M. Bootwalla, J. L. Ji, L. S. Shen, J. B. Miller, L. A. Kim, P. N. Tariot, K. A. Johnson, E. M. Reiman \& Y. T. Quiroz (2019) Resistance to autosomal dominant Alzheimer's disease in an APOE3 Christchurch homozygote: a case report. Nature Medicine, 25, $1680-+$. 